\title{
Phenotypic variation and correlation of traits in Philippine hybrid rice varieties
}

\author{
$\bowtie$ Aldrin Y. Cantila, Aizel Mae L. Fordan and Isagane V. Boholano
}

Philippine Rice Research Institute, Bual Norte, Midsayap 9410, Philippines

\begin{tabular}{|c|c|}
\hline ARTICLE INFO OPEN & ract \\
\hline $\begin{array}{l}\text { Article history: } \\
\text { Received : } 17 \text { February } 2019 \\
\text { Accepted : } 24 \text { May } 2019 \\
\text { Published: } 30 \text { June } 2019 \\
\end{array}$ & \multirow{3}{*}{$\begin{array}{l}\text { Understanding the phenotypic variation and correlation in hybrid rice varieties will lead to proper } \\
\text { utilization of these genetic resources. Grain yield (GY), the primary trait, and its secondary traits such as } \\
\text { days to } 50 \% \text { flowering (DF), days to maturity (DM), grain length (GL), grain weight (GW), number of } \\
\text { filled grains panicle } \mathrm{e}^{-1} \text { (NFGP), one thousand grain weight (OTGW) panicle length (PL), panicle weight } \\
\text { (PW), spikelet fertility (SF), and spikelet number panicle }{ }^{-1} \text { (SNP) of } 13 \text { hybrid rice in two environments } \\
\text { (E1 and E2) were analyzed using combined analysis of variance (ANOVA) and correlation analysis. High } \\
\text { significant variation was found among hybrids (G) in all traits except for GW while there was at least } \\
\text { significant result among environments (E) in DF, DM, GL, GW, PW, and OTGW, and in GxE in DF, DM, } \\
\text { GW, NFGP, PW, and SNP. Therefore, E1 hybrids were early flowering and maturing, had longer, wider, } \\
\text { and more grains, had longer panicles, and higher yield while in E2 hybrids were late flowering and } \\
\text { maturing, and had heavier grains. However, among the } 13 \text { hybrid rice, M1 had the highest GY and GL in } \\
\text { each environment with a mean of } 9.57 \mathrm{t} \text { ha }^{-1} \text { and } 9.75 \mathrm{~mm} \text {, respectively. M1, therefore, can be } \\
\text { recommended to farmers for varietal utilization. Correlation analysis, on the other hand, found } 15 \text { and } 17 \\
\text { significant correlations in E1 and E2, respectively. Of the correlation results, it was found out that among } \\
\text { the secondary traits, only NFGP was consistently, significantly and positively correlated with GY in two } \\
\text { environments. The result implied that attaining higher yield in hybrid rice cultivation can be possible by } \\
\text { giving more attention to the plants during the grain filling stage. }\end{array}$} \\
\hline & \\
\hline & \\
\hline
\end{tabular}

Copyright:

(c) (7)

(O2019 by authors and BAURES. This work is licensed under the Creative Commons Attribution International License (CC By 4.0).

\section{Introduction}

The world population is expected to reach 9 billion people by 2050 (FAO, 2009) and in order to evade hunger, the rice production needs to increase by almost 44 million metric tons (Tester and Langridge, 2010). In the Philippines, the department of agriculture aims to increase rice production by using one of the strategies like utilizing hybrid rice to be planted to at least 1 million hectares of rice farms in the coming years (Desamero and Manigbas, 2017; Philstar, 2016). Hybrid rice has a $15 \%$ to $30 \%$ yield advantage over modern inbred rice varieties (Yuan, 1986). The first Philippine hybrid research was realized on the 1990s when International Rice Research Institute (IRRI) obtained hybrid parent materials suitable in tropical conditions and then they released Magat (PSB Rc 26H) on 1994 (Gaspar et al., 2007). Three years after, IRRI developed Mestizo 1 or M1 (PSB Rc 72H). M1 has been cultivated and adopted by farmers according to Gaspar et al., (2007). Consequently, a total of 102 hybrids were registered and released from 1999 to 2018 (NSIC, 2019). The Philippine Rice Research Institute (Phil Rice) has still focused on the development of cytoplasmic male sterility-based three-line hybrids, thermo-sensitive genetic male sterile-based two-line hybrid rice and hybrid nucleus and breeder seed production research that aims to produce more of superior parents to develop a hybrid (Desamero and Manigbas, 2017). A survey was conducted on the seed adoption rates of all Philippine rice varieties by Sombilla and Quilloy (2014). They reported that out of 4,690,000 hectares of rice, only $4.8 \%$ was cultivated with hybrid, $39.9 \%$ with certified inbred, $52.3 \%$ with farmers' or good seeds, and 3.1\% with traditional or native varieties. Still, hybrid rice varieties had been adopted at a low rate, which was similar to the previous report on hybrid rice' adoption survey by Casiwan et al. (2003). That is why; the study was done aiming to define the phenotypic analysis on 13 hybrid rice, to determine one or more suitable hybrid/s, and to find correlation in hybrid traits.

\section{Materials and Methods}

\section{Experimental materials}

Hybrid varieties were acquired from different institutions of the country that are registered and commercially released by the NSIC-Philippines. These varieties have a common name of Mestizo (M). M1 and M32 were developed from IRRI, M12 and M13 from Philippine-Sino Center for Agricultural Technology (Phil SCAT), M20 and M55 from Phil Rice, M28 and M51 from Seed works, M52 and M59 from Syngenta, M6 from SL Agritech, M46 from Bayer Crop Science, 
and M60 from Advanta India Limited. IRRI, Phil SCAT, and Phil Rice are considered public institutions while Seed works, Syngenta, SL Agritech, Bayer Crop Science, and Advanta India Limited are private firms. These 13 hybrid rice varieties were considered as experimental materials.

\section{The environment and field layout}

The set-up had two environments. One was located at Midsayap, Cotabato with global positioning system (GPS) points of $7^{\circ} 10^{\prime} 42.5^{\prime \prime} \mathrm{N} 124^{\circ} 30^{\prime} 04.5^{\prime \prime} \mathrm{E}$ (E1) and another was at Isulan, Sultan Kudarat with corresponding GPS points of $6^{\circ} 34^{\prime} 33.7^{\prime \prime N}$ $124^{\circ} 36^{\prime} 47.7^{\prime \prime E} 9$ (E2). E1 experimental materials were planted from April 16 to July 18, 2018, while E2 experimental materials were from June 25 to September 28, 2018. Every 13 experimental materials were carried out in randomized complete block design in three replications.

\section{Crop management}

The crop establishment, plowing, rotating, final leveling, transplanting, weeding, irrigation and harvesting were done following the methodology in the Palay Check system for irrigated lowland rice by Phil Rice (2007). The chemical application was also employed to protect rice plants. Fertilizers were applied in a rate of $90 \mathrm{kgha}^{-1}$ of 14-14-14 and $10 \mathrm{kgha}^{-1}$ of 0-0-60 at basal, $60 \mathrm{kgha}^{-1}$ of 46-0-0 at tillering and $100 \mathrm{kgha}^{-1}$ of $21-0-0-24$ at panicle initiation based on the soil analysis.

\section{Data gathered}

The primary trait GY was computed in this formula: [Panicle number per $\mathrm{m}^{2} \mathrm{x}$ spikelet number panicle- ${ }^{1} \mathrm{x}$ spikelet fertility (\%) x 1000 grain weight $\left.(\mathrm{g}) \times 10^{-2}\right] \div$ 1000 ( Phil Rice, 2007) while the secondary traits such as days to $50 \%$ flowering (DF), days to maturity (DM), grain length (GL) in $\mathrm{mm}$, grain width $(\mathrm{GW})$ in $\mathrm{mm}$, number of filled grains panicle ${ }^{-1}$ (NFGP), one thousand grain weight $(\mathrm{OTGW})$ in $\mathrm{g}$, panicle length $(\mathrm{PL})$ in $\mathrm{cm}$, panicle weight (PW) in $\mathrm{g}$, spikelet fertility (SF) in \% and spikelet number panicle ${ }^{-1}$ (SNP) was gathered following the methodology in the standard evaluation system for rice (IRRI, 2013). On the other hand, temperature data was taken from the environment's weather station (Table 2).

Table 1. Thirteen NSIC released varieties (hybrids) with their source were used as experimental materials

\begin{tabular}{ccccc}
\hline $\begin{array}{c}\text { Sample } \\
\text { number }\end{array}$ & Registered code & $\begin{array}{c}\text { Variety } \\
\text { name }\end{array}$ & $\begin{array}{c}\text { Year } \\
\text { released }\end{array}$ & Source \\
\hline 1 & NSIC Rc 72H & M1 & 1997 & IRRI $^{1}$ \\
2 & NSIC Rc 132H & M6 & 2004 & SL Agritech $^{2}$ \\
3 & NSIC Rc 174H & M12 & 2008 & PhilSCat $^{1}$ \\
4 & NSIC Rc 176H & M13 & 2008 & PhilSCat $^{1}$ \\
5 & NSIC Rc 204H & M20 & 2009 & PhilRice $^{1}$ \\
6 & NSIC Rc 236H & M28 & 2010 & Seedworks $^{2}$ \\
7 & NSIC Rc 250H & M32 & 2011 & IRRI $^{1}$ \\
8 & NSIC Rc 314H & M46 & 2013 & Bayer Crop $_{\text {Science }}^{2}$ \\
9 & NSIC Rc 350H & M51 & 2013 & Seedworks $^{2}$ \\
10 & NSIC Rc 362H & M52 & 2014 & Syngenta $^{2}$ \\
11 & NSIC Rc 368H & M55 & 2014 & PhilRice $^{1}$ \\
12 & NSIC Rc 376H & M59 & 2014 & Syngenta $^{2}$ \\
13 & NSIC Rc 378H & M60 & 2014 & Advanta India $_{\text {Limited }}$ \\
\hline${ }^{1}$ public institution; ${ }^{2}$ private firms/institution & &
\end{tabular}

${ }^{1}$ public institution; ${ }^{2}$ private firms/institution
Table 2. Temperature data taken in two environments were used in the study

\begin{tabular}{|c|c|c|c|c|c|c|c|c|}
\hline \multirow{2}{*}{$\begin{array}{c}\text { Temperature } \\
\left({ }^{\circ} \mathrm{C}\right)\end{array}$} & \multicolumn{4}{|c|}{ E1 } & \multicolumn{4}{|c|}{ E2 } \\
\hline & April & May & June & July & June & July & August & Sept \\
\hline Minimum & 22.6 & 22.8 & 22.8 & 22.3 & 22.5 & 22 & 22 & 22.2 \\
\hline Maximum & 33.4 & 32.7 & 32.1 & 31.6 & 31.7 & 31.2 & 31.3 & 31.6 \\
\hline Mean & 28 & 27.7 & 27.4 & 26.9 & 27.1 & 26.6 & 26.6 & 26.9 \\
\hline
\end{tabular}

\section{Statistical analyses}

XLstat software (Addinsoft, 2010) gave the overall mean, means with its standard error (Table 3) and Kolmogorov-Smirnov (K-S) normality test for the data of each trait per environment. Mantel's and correlation tests were also derived using the same software. STAR 2.01 (2014) software, on the other hand, computed the combined analysis of variance (ANOVA) with corresponding F-test of each trait in two environments.

Table 3. Overall mean, mean with its standard error of each trait in two environments were used for the comparison in the study

\begin{tabular}{cccccc}
\hline Traits & E1 & $\begin{array}{c} \pm \text { Standard } \\
\text { error }\end{array}$ & E2 & $\begin{array}{c} \pm \text { Standard } \\
\text { error }\end{array}$ & $\begin{array}{c}\text { Overall } \\
\text { mean }\end{array}$ \\
\hline D50F & 68 & 0.73 & 71 & 0.5 & 69.5 \\
\hline DM & 113 & 0.66 & 117 & 0.45 & 115 \\
\hline GL & 9.5 & 0.1 & 8.7 & 0.07 & 9.1 \\
\hline GW & 2.5 & 0.03 & 2.4 & 0.03 & 2.45 \\
\hline NFGP & 126.4 & 4.35 & 117.9 & 3.76 & 122.15 \\
\hline OTGW & 23.6 & 0.3 & 27.1 & 0.57 & 25.35 \\
\hline PL & 29.3 & 0.64 & 25.3 & 0.28 & 27.3 \\
\hline PW & 3.4 & 0.04 & 3.7 & 0.1 & 3.55 \\
\hline SF & 73.3 & 1.37 & 70.6 & 1.22 & 71.95 \\
\hline SNP & 171.4 & 3.86 & 168.3 & 5.66 & 169.85 \\
\hline GY & 6.83 & 0.42 & 6.55 & 0.28 & 6.69 \\
\hline
\end{tabular}

\section{Results and Discussion}

The validity of the data

Prior to the ANOVA, the data has to be tested with the $\mathrm{K}-\mathrm{S}$ normality test to determine whether it is express in a normal pattern (Smirnov, 1939; Kolmogoroff, 1941). Normality test was utilized by Cantila et al. (2017) when they studied the quantitative traits in rice. K-S normality test had a range of $p$-values from 0.051 to 0.993 (Fig. 1 and 2) in 11 traits in two environments. Results mean that the phenotypic data of hybrids was normally distributed in each trait. The data in each environment was also analyzed by Mantel's test (Mantel, 1967). It determines the correlation between the overall data set of E1 and E2. Mantel's test had a $p$-value of 0.76 with a correlation result of 0.035 (Fig. 3), indicating a low correlation in data sets. The low correlation of data sets can be due to the temperature difference in the two environments. E1 (April to July) had a mean temperature of $27{ }^{\circ} \mathrm{C}$, which was $0.7{ }^{\circ} \mathrm{C}$ hotter than in E2 (June to September) with a mean temperature of $26.8{ }^{\circ} \mathrm{C}$ (Table 2). Hotter temperatures occur commonly during the middle weeks of April to May as experienced by Manigbas and Sebastian (2007) in their rice studies; which also explains the condition of E1 in the study. Temperature is an important environmental factor that affects the developmental processes in plants such as rice (Cantila and Quitel, 2017; Lang et al., 2015). The 
data in each environment, therefore, was valid and can be further analyzed.

\section{Analysis of hybrid phenotypes}

The significant difference between hybrids in different environments was statistically supported by the combined ANOVA (Table 4 and 5). It was found out that there was significance or high significance in DF, DM, GL, GW, PW, and OTGW for the environment and in DF, DM, GW, NFGP, PW, and SNP for the genotype by environment interaction (Table 4 and 5). The hybrids in E1 had higher value in GL (9.5 mm), GW (2.5 mm), NFGP (126.4), PL (29.3 cm), SF (73.3\%), SNP (171.4) and GY (6.83 tha $^{-1}$ ) while hybrids in E2 had higher values in DF (71 days), DM (117 days), OTGW (27.1 g) and PW (3.7 g) (Figure 4). Results implied that hybrids in E1 had longer, wider, and more grains, earlier days to flower and mature, longer panicles, and higher yield while hybrids in hybrids were flowering and maturing, and had heavier grains. Also, significant variation was found among hybrids in all traits except for GW. GW in $\mathrm{K}-\mathrm{S}$ normality test had a $p$-value of 0.051 in $\mathrm{E} 2$, a near non-significance value as the test requires $p$-value should be > alpha 0.05 . Among the hybrids in E1, M1 had longer grains, longer and heavier panicles, and higher yield $(\mathrm{GL}=10.3 \mathrm{~mm}, \mathrm{NFGP}=158.7, \mathrm{PL}=33.4 \mathrm{~cm}$, $\mathrm{PW}=3.6 \mathrm{~g}, \mathrm{SNP}=199.2$, and $\mathrm{GY}=10.81 \mathrm{tha}^{-1}$ ) (Figure 4). While M6 had heavier grains (OTGW=26.3 g), M52 had heavier panicles ( $\mathrm{PW}=3.6 \mathrm{~g})$. $\mathrm{M} 12$ was early and flowering and maturing $(\mathrm{DF}=63$ days and $\mathrm{DM}=107$ days) Fig. 4. In contrast to M12, M20 was late flowering and maturing with longer grains $(\mathrm{DF}=74.7$ days and $\mathrm{DM}=117.3$, and $\mathrm{GL}=10.3 \mathrm{~mm}$ ) (Fig. 4). Lastly, M60 had a higher $\%$ of fertile spikelets $(\mathrm{SF}=82.4 \%)$ (Fig. 4). On the other hand, among the hybrids in E2, M1 had longer grains, and higher $\%$ of fertile spikelets and yield $\left(\mathrm{GL}=9.2 \mathrm{~mm}, \mathrm{SF}=79.4 \%\right.$, and $\mathrm{GY}=8.33 \mathrm{tha}^{-1}$ ) (Fig. 4). While M6 was early flowering and maturing with heavier grains $(\mathrm{DF}=67.3$ days, $\mathrm{DM}=113.7$ days, and OTGW=32.9 g), M12 was late flowering and maturing with heavier panicles ( $\mathrm{DF}=75$ days, $\mathrm{DM}=119.3$ days, and PW=4.7 g) (Fig. 4). Lastly, M28 had longer panicles and more spikelets $(\mathrm{PL}=26.9 \mathrm{~cm}$ and $\mathrm{SNP}=214.7)$, and M51 had more filled grains $(\mathrm{NFGP}=158.1)$ (Fig. 4). Despite the effect of the environment to hybrids, M6 consistently had the heaviest grains in two environments with a mean of $29.6 \mathrm{~g}$ in OTGW. Similarly, M1 had the highest GY and GL in the two environments with a mean of 9.57 tha $^{-1}$ and $9.75 \mathrm{~mm}$ (Fig. 5), respectively. M1 has a $68.7 \%$ milling recovery and soft eating quality (Phil Rice, 2019). It is one of the best rice hybrids developed in the Philippines according to rice farmers (Phil Rice, 2018; Philstar, 2002). M1, therefore, can be recommended to farmers for varietal utilization.
Table 4. ANOVA and F-test of DF, GL, GW and NFGP determined the significance in the study

\begin{tabular}{|c|c|c|c|c|}
\hline Traits & SV & SS & MS & F-value \\
\hline \multirow{5}{*}{ DF } & $\mathrm{E}$ & 240.63 & 240.63 & $55.04 * *$ \\
\hline & Rep/E & 17.49 & 4.37 & $0.84^{\mathrm{ns}}$ \\
\hline & $\mathrm{G}$ & 584.87 & 48.74 & $9.34 * *$ \\
\hline & GxE & 295.54 & 24.63 & $4.72 * *$ \\
\hline & P. error & 250.51 & 5.22 & \\
\hline \multirow{5}{*}{ DM } & $\mathrm{E}$ & 308.01 & 308.01 & $24.59 * *$ \\
\hline & Rep/E & 50.10 & 12.53 & $1.84^{\mathrm{ns}}$ \\
\hline & $\mathrm{G}$ & 371.21 & 30.93 & $4.55 * *$ \\
\hline & GxE & 211.15 & 17.6 & $2.59 * *$ \\
\hline & P. error & 326.56 & 6.80 & \\
\hline \multirow{5}{*}{ GL } & $\mathrm{E}$ & 10.41 & 10.41 & $79.60 * *$ \\
\hline & Rep/E & 0.523 & 0.131 & $1.86^{\mathrm{ns}}$ \\
\hline & $\mathrm{G}$ & 13.96 & 1.16 & $16.54^{* * *}$ \\
\hline & GxE & 3.32 & 0.28 & $3.93^{* *}$ \\
\hline & P. error & 3.38 & 0.07 & \\
\hline \multirow{5}{*}{ GW } & $\mathrm{E}$ & 0.23 & 0.23 & $12.27 *$ \\
\hline & Rep/E & 0.075 & 0.019 & $0.79^{\mathrm{ns}}$ \\
\hline & $\mathrm{G}$ & 0.68 & 0.06 & $2.39^{\mathrm{ns}}$ \\
\hline & GxE & 0.28 & 0.023 & $0.98^{\mathrm{ns}}$ \\
\hline & P. error & 1.14 & 0.024 & \\
\hline \multirow{5}{*}{ NFGP } & $\mathrm{E}$ & 1383.49 & 1383.5 & $1.87^{\mathrm{ns}}$ \\
\hline & Rep/E & 2958.90 & 739.73 & $2.17^{\mathrm{ns}}$ \\
\hline & $\mathrm{G}$ & 12334.83 & 1027.9 & $3.02 * *$ \\
\hline & GxE & 16261.24 & 1355.1 & $3.98 * *$ \\
\hline & P. error & 16346.41 & 340.55 & \\
\hline
\end{tabular}

$\mathrm{E}=$ environment, Rep=replication, $\mathrm{G}=$ genotype, $\mathrm{GxE}=\mathrm{G}$ by $\mathrm{E}$ interaction, P.error=pooled error, df: $(E=1$; Rep/E=4; $\mathrm{G}$ and $\mathrm{GxE}=12$; P. error $=48), * *=$ highly significant $(1 \% \mathrm{~F}-\mathrm{tab}), *=$ significant $(5 \%-\mathrm{F}-$ tab) and ${ }^{\mathrm{ns}}=$ not significant

Table 5. ANOVA and F-test in OTGW, PL, PW, SF, SNP and GY determined the significance in the study

\begin{tabular}{|c|c|c|c|c|}
\hline Traits & SV & SS & MS & F-value \\
\hline \multirow{5}{*}{ OTGW } & $\mathrm{E}$ & 244.86 & 244.86 & $30.12 * *$ \\
\hline & Rep/E & 32.52 & 8.13 & $2.57^{\mathrm{ns}}$ \\
\hline & $\mathrm{G}$ & 349.73 & 29.14 & $9.20^{* *}$ \\
\hline & GxE & 66.07 & 5.51 & $1.74^{\mathrm{ns}}$ \\
\hline & P. error & 152.11 & 3.17 & \\
\hline \multirow{5}{*}{ PL } & $E$ & 317.46 & 317.46 & $7.39^{\mathrm{ns}}$ \\
\hline & Rep/E & 171.93 & 42.98 & $7.89 * *$ \\
\hline & $\mathrm{G}$ & 203.18 & 16.93 & $3.11 * *$ \\
\hline & GxE & 74.94 & 6.24 & $1.15^{\mathrm{ns}}$ \\
\hline & P. error & 261.50 & 5.45 & \\
\hline \multirow{5}{*}{ PW } & $E$ & 1.79 & 1.79 & 9.79* \\
\hline & Rep/E & 0.731 & 0.183 & $1.49^{\mathrm{ns}}$ \\
\hline & $\mathrm{G}$ & 6.09 & 0.51 & $4.12 * *$ \\
\hline & GxE & 6.05 & 0.50 & $4.10 * *$ \\
\hline & P. error & 5.91 & 0.123 & \\
\hline \multirow{5}{*}{ SF } & $\mathrm{E}$ & 143.24 & 143.24 & $2.55^{\mathrm{ns}}$ \\
\hline & Rep/E & 224.54 & 56.13 & $1.63^{\mathrm{ns}}$ \\
\hline & $\mathrm{G}$ & 2031.27 & 169.27 & $4.91 * *$ \\
\hline & GxE & 952.71 & 79.39 & $2.30^{\mathrm{ns}}$ \\
\hline & P. error & 1655.72 & 34.49 & \\
\hline \multirow{5}{*}{ SNP } & $\mathrm{E}$ & 177.30 & 177.3 & $0.20^{\mathrm{ns}}$ \\
\hline & Rep/E & 3459.57 & 864.89 & $1.93^{\mathrm{ns}}$ \\
\hline & $\mathrm{G}$ & 23453.26 & 1954.4 & $4.35^{* *}$ \\
\hline & GxE & 18930.89 & 1577.6 & $3.51 * *$ \\
\hline & P. error & 21550.47 & 448.97 & \\
\hline \multirow{5}{*}{ GY } & $\mathrm{E}$ & 1.51 & 1.51 & $0.24^{\mathrm{ns}}$ \\
\hline & Rep/E & 24.66 & 6.16 & $2.13^{\mathrm{ns}}$ \\
\hline & $\mathrm{G}$ & 161.43 & 13.45 & $4.65^{* *}$ \\
\hline & GxE & 43.76 & 3.65 & $1.26^{\mathrm{ns}}$ \\
\hline & P. error & 138.93 & 2.89 & \\
\hline
\end{tabular}

$\mathrm{E}=$ environment, Rep=replication, $\mathrm{G}=$ genotype, $\mathrm{GxE}=\mathrm{G}$ by $\mathrm{E}$ interaction, P.error=pooled error, df: $(\mathrm{E}=1 ; \mathrm{Rep} / \mathrm{E}=4 ; \mathrm{G}$ and $\mathrm{GxE}=12$; P. error $=48), * *=$ highly significant $(1 \% \mathrm{~F}-\mathrm{tab}), *=$ significant $(5 \%-\mathrm{F}-$ tab) and ${ }^{\mathrm{ns}}=$ not significant. 

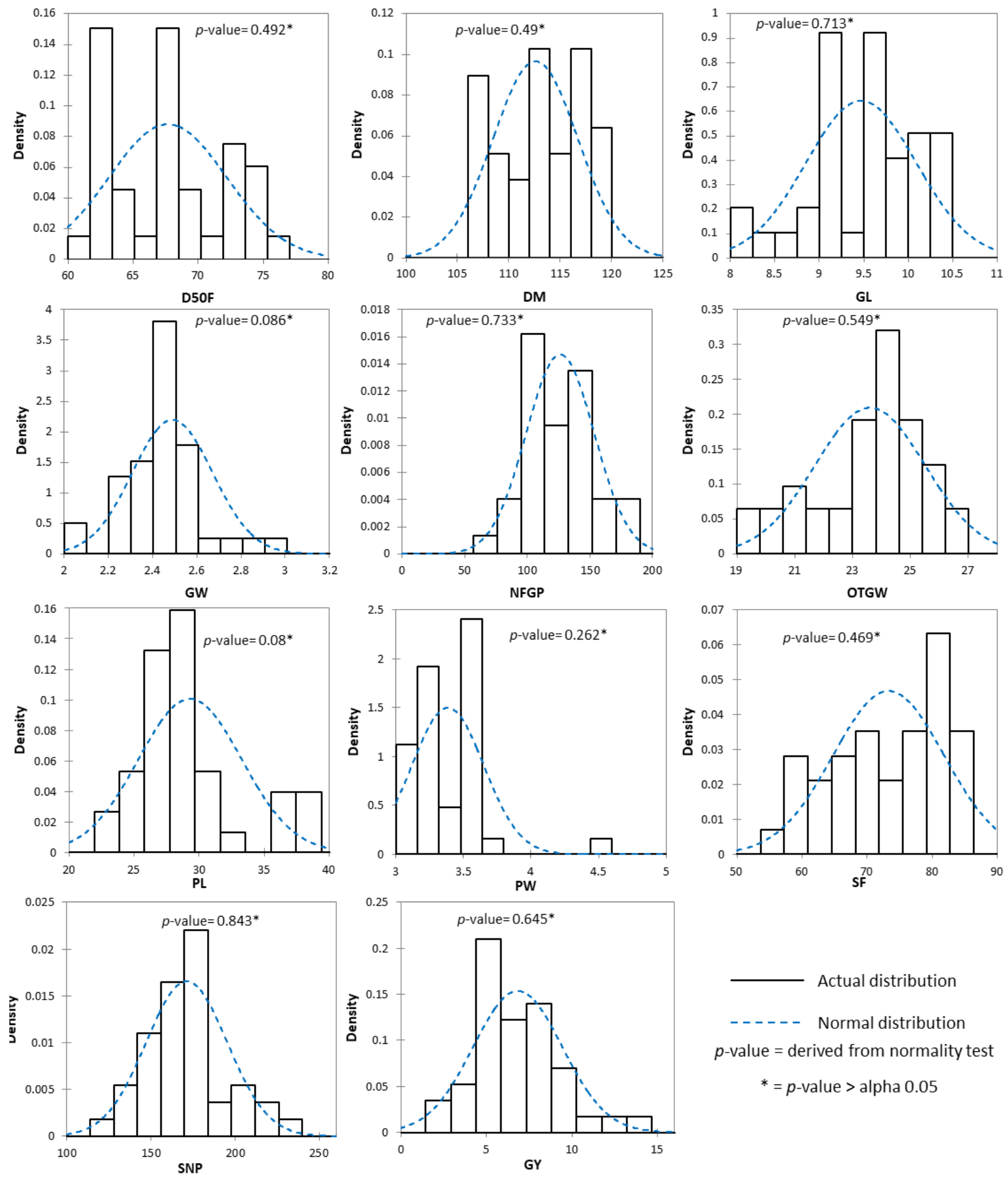

Fig. 1. Histogram in 11 traits with corresponding $p$-value of normality test showed the distribution of data in E1, Midsayap, Cotabato 

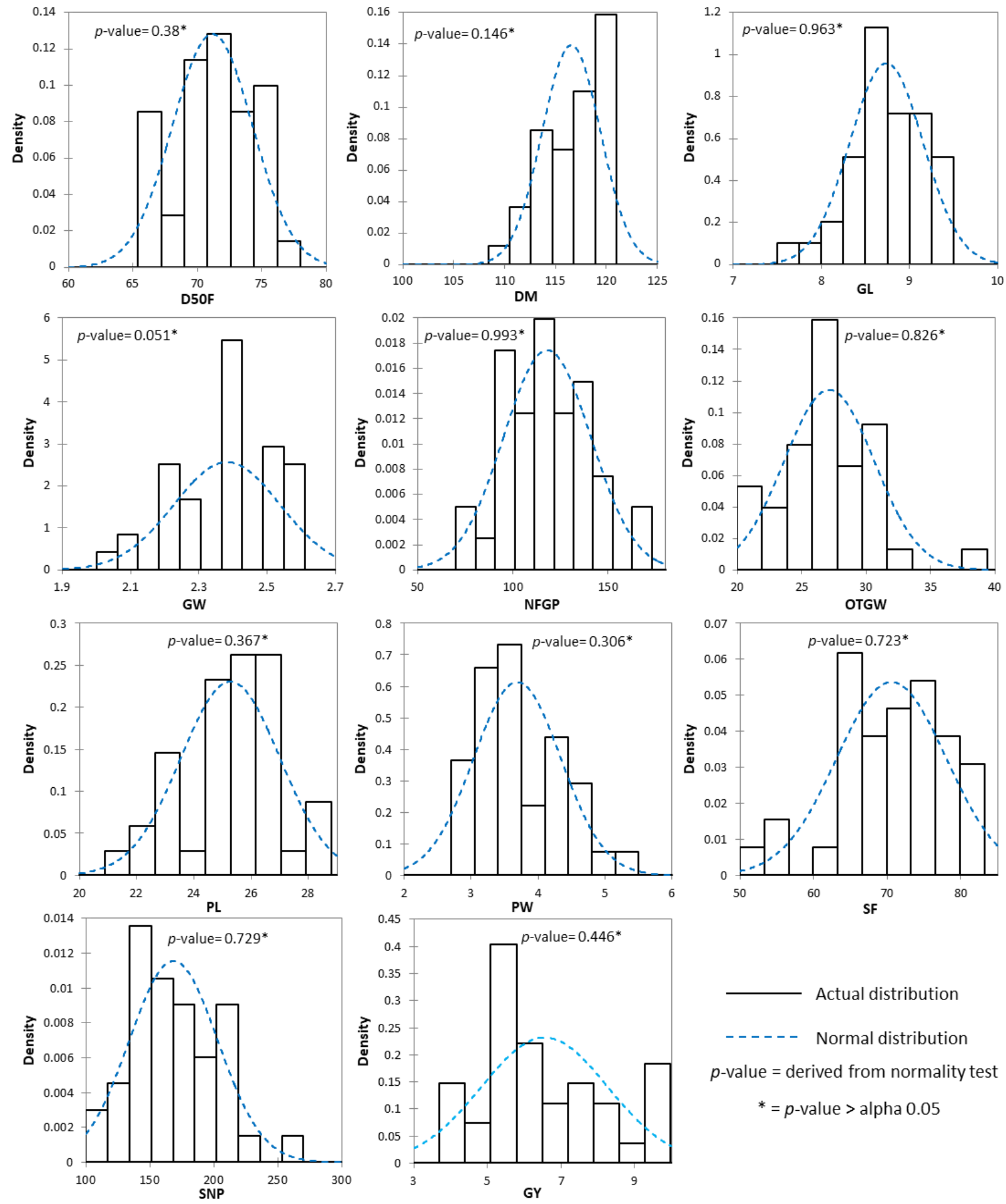

$p$-value $=$ derived from normality test

* $=p$-value $>$ alpha 0.05

Fig. 2. Histogram in 11 traits with corresponding $p$-value of normality test showed the distribution of data in E2, Isulan, Sultan Kudarat 

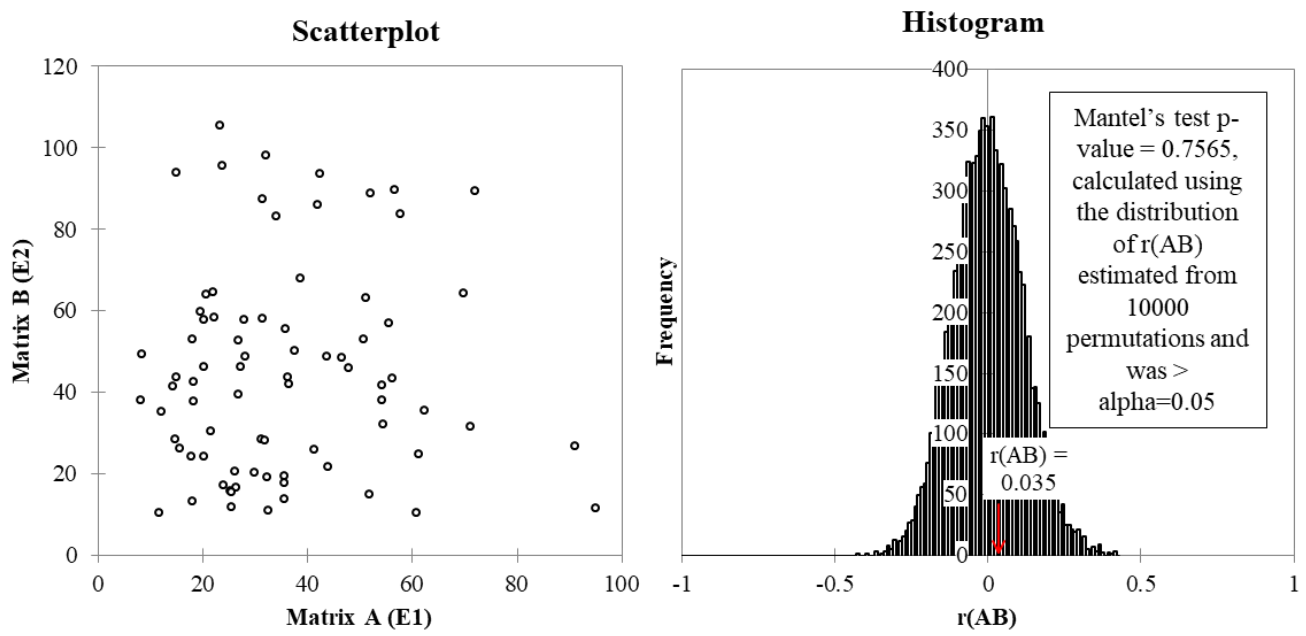

Fig. 3. Scatterplot and histograms with corresponding Mantel's test showed the non-correlation of two data sets in each environment
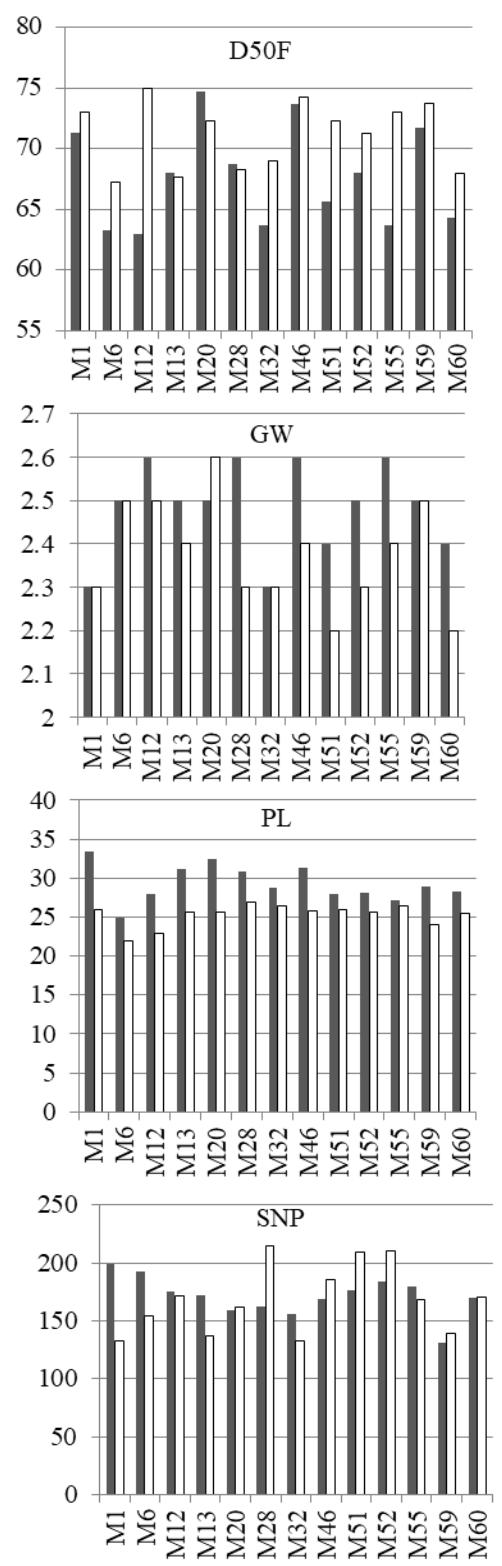
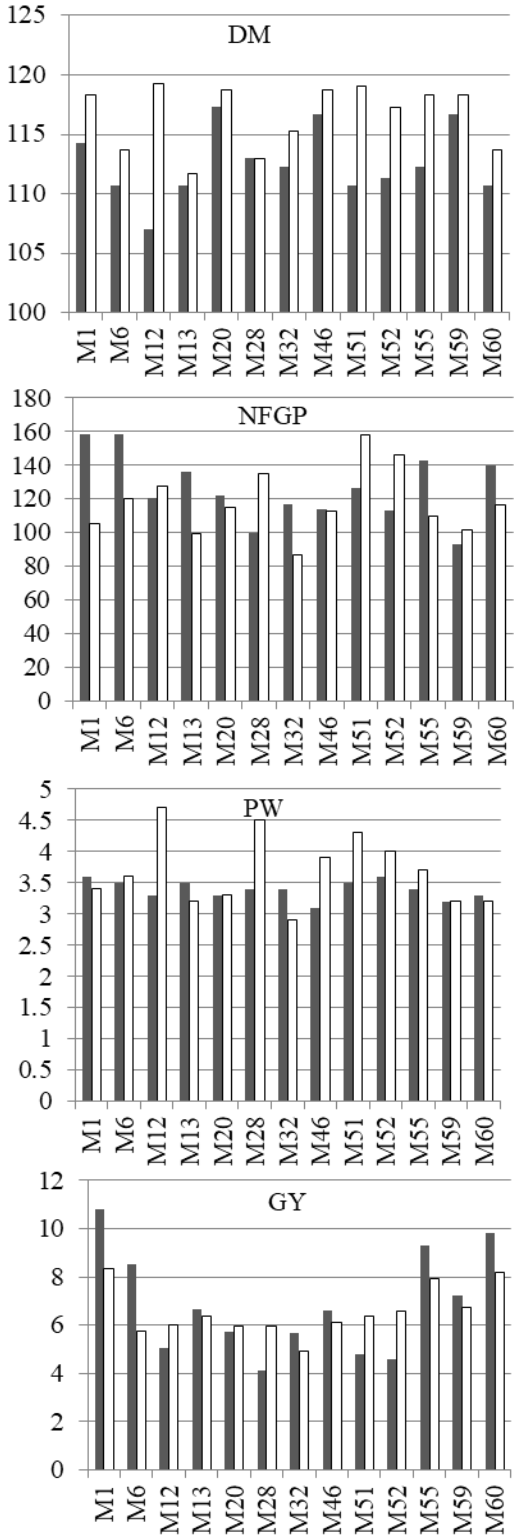

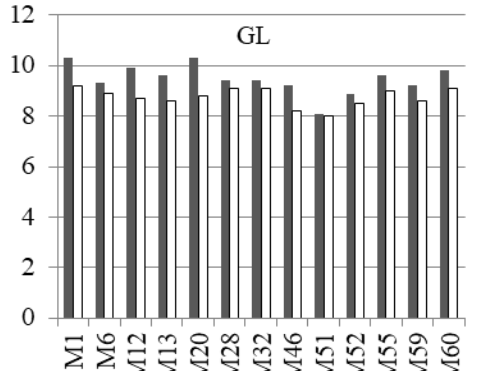

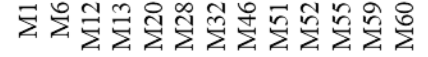
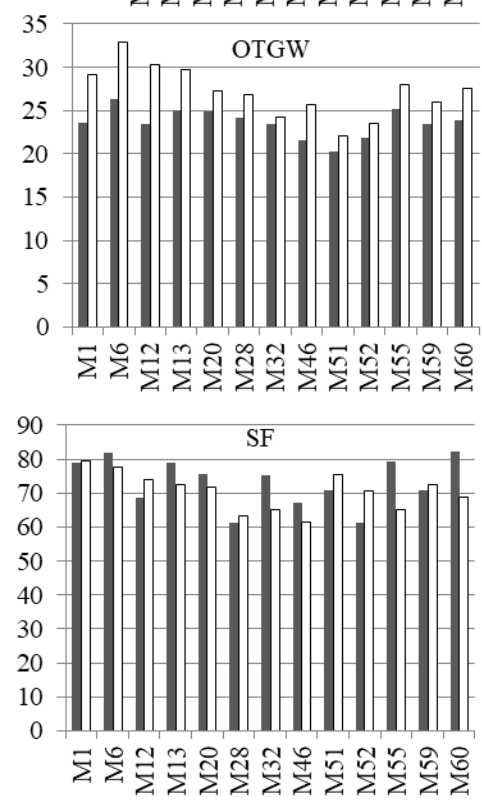

Legend:

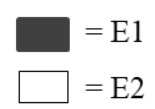

Fig. 4. Means of 13 hybrids in 11 traits showed the difference between genotypes 


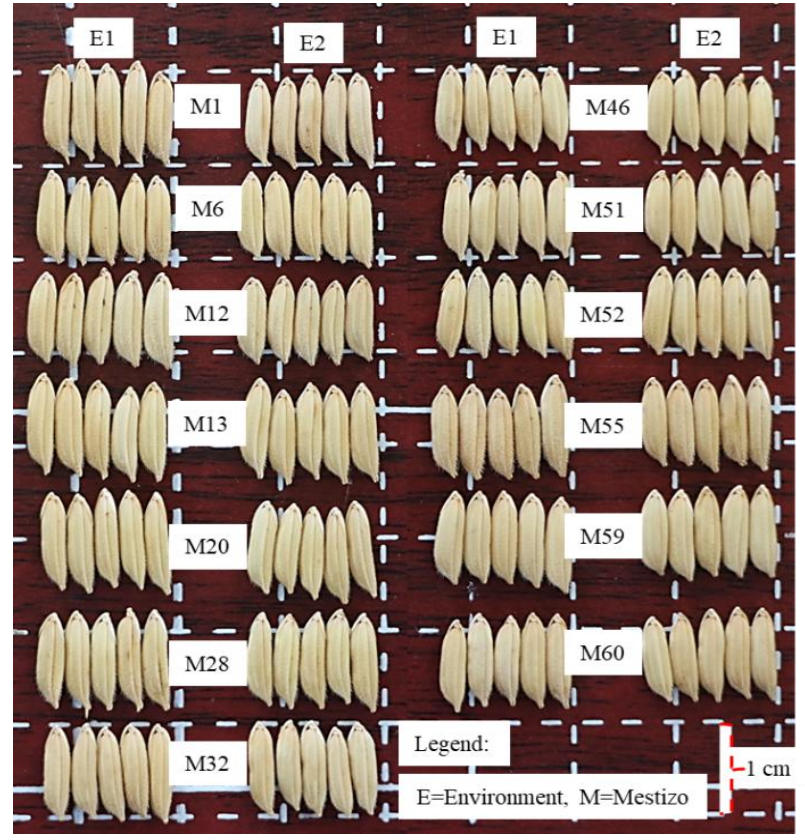

Fig. 5. Samples of hybrid rice grains showed the phenotypic variation in grains

\section{Correlation in traits}

Correlation (r) analysis was based on Pearson's coefficient (Pearson, 1895) and the interpretation of the result was based on Taylor (1990). Correlation means low if $\mathrm{r}=0.01$ to 0.35 , moderate if $\mathrm{r}=0.36$ to 0.67 , and high if $r=0.68$ to 0.99 . Out of 55 trait combinations in each environment, 15 and 17 significant correlations were found in E1 and E2, respectively (Fig. 6). E1 had 12 positive and three negative correlations out of 15 significant correlations and E2 had eight positive and nine negative correlations out of 17 significant correlations (Fig. 6). In E1, high and positive correlation was seen to traits GY and NFGP, GY and SF, SF and NFGP, and NFGP and SNP; moderate and positive correlation to GL and OTGW, GL and PL, OTGW and SF, PW and SNP, SF and SNP, and GY and SNP; low and positive correlation to $\mathrm{DF}$ and $\mathrm{PL}$, and $\mathrm{PW}$ and NFGP; low and negative correlation to DF and NFGP, DF and SF, and DM and SNP. In E2, however, high and positive correlation was found to traits DF and DM, and NFGP and SNP; moderate and positive correlation to GY and OTGW, GW and OTGW, PW and NFGP, and PW and SNP; low and positive correlation to DM and PW, and GY and NFGP; moderate and negative correlation to DM and GL, GL and NFGP, GL and PW, GL and SNP, GW and SNP, OTGW and PL, and PL and SF; low and negative correlation to GW and NFGP, and SF and SNP. Though these combinations had significance, high correlations were often given emphasis in any rice research. Cantila et al., (2017) had used the same approach in their correlation result. In E1, the correlation between SF to GY was also noted by Hasan et al., (2015) based on 24 hybrid rice genotypes, while NFGP to GY by Bhadru et al., (2012) based on 93 rice genotypes (includes 68 hybrids) and Cantila et al. (2016) based on 29 rice genotypes (includes four hybrids). On the other hand, the correlation of NFGP to SNP and SF is understood as when there are more spikelets in a panicle, the more chances the grains are filled and makes the fertility \% higher. In E2, however, the DF and DM correlation mean that when longer days are required in flowering, the longer days it requires maturity. This finding was similar to Uddin et al., (2007) when they studied the correlation of traits based on 50 hybrids. Another correlation such as NFGP to SF was already explained earlier. Overall, among the secondary traits, only NFGP had a significant and positive correlation to GY in two environments. This indicates that a higher yield in hybrid rice is possible when hybrids have a higher number of filled grains.

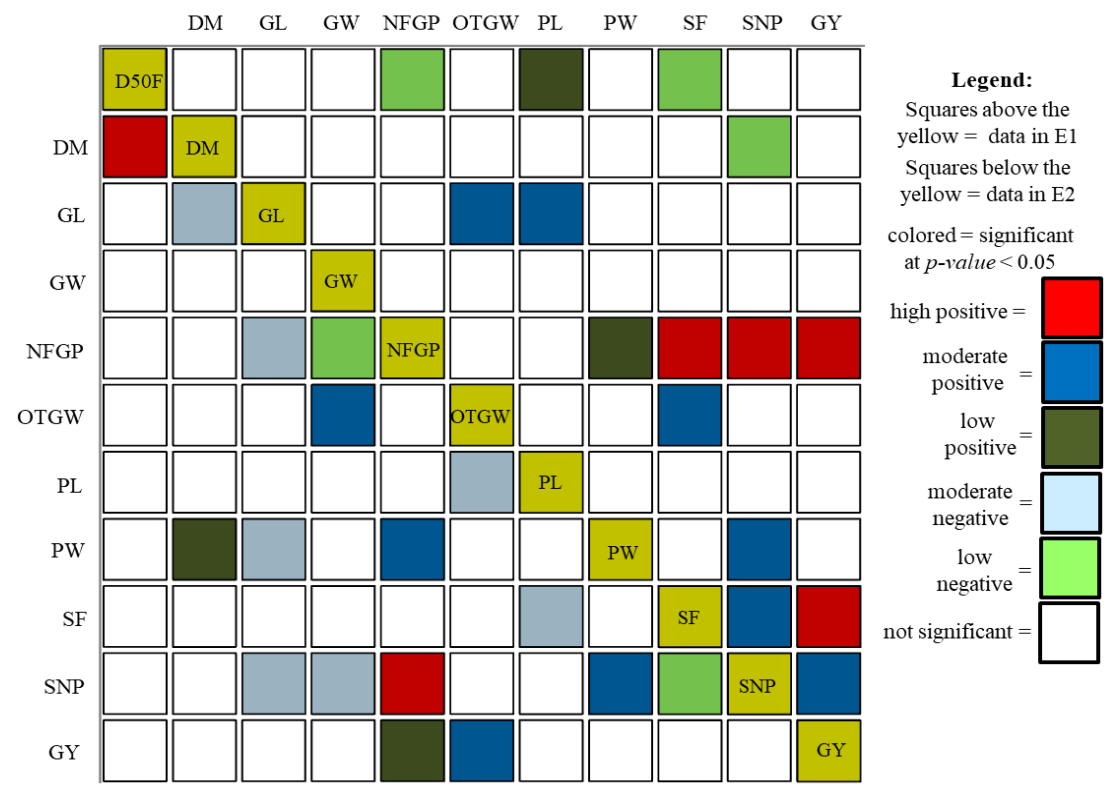

Fig. 6. Correlation based on color map showed the relationship of traits in each environment. 


\section{Summary and Conclusion}

High significant variation (1\%) was found among hybrids in all traits except for GW while at the least significance $(5 \%)$ among environments $(\mathrm{E})$ in six traits and in GxE in six traits. Hybrids in each environment, therefore, showed different phenotypes. The most notable was M1 among the 13 hybrid rice. M1 had the highest GY and GL in each environment with a mean of 9.57 tha $^{-1}$ and $9.75 \mathrm{~mm}$, respectively. This variety can be recommended to farmers for varietal utilization. On the other hand, correlation analysis found 32 significant correlations in two environments but the most noted was that NFGP was consistently, significantly and positively correlated with GY in two environments. The result implied that increasing higher yield in hybrid rice cultivation can be possible by giving more attention to the plants during the grain filling stage.

\section{Acknowledgement}

The authors are grateful for Elmer Bedia, field worker of the study, and the Philippine Rice Research Institute for the financial assistance.

\section{References}

Addinsoft. 2010. XLSTAT. Data analysis and statistics software for Microsoft Excel. Paris, France. www.xlstat.com

Bhadru, D., Reddy, D.L. and Ramesha, M.S., 2012. Correlation and path analysis of yield and yield components in hybrid rice (Oryza sativa L.). Agricultural Science Digest, 32 (3): 199203

Cantila, A.Y., Abdula, S.E. and Candalia, H.J.C., 2017. Study of the quantitative traits in registered inbred rice (Oryza sativa L.) using different statistical parameters. Philippine Journal of Science, 146(4):387-393.

Cantila, A.Y. and Quitel A.J.R., 2017. Statistical Analysis of Foreign Rice Phenotypes under Different Seasons of the Philippines. Journal of Advanced Applied Scientific Research, 1 (12). http://joaasr.com/index.php/joaasr/article/view/172

Cantila, A.Y., Abdula, S.E., Candalia, H.J.C. and Balleras, G.D., 2016. Multiple statistical tools for divergence analysis of rice (Oryza sativa L.) released varieties. The Philippine Statistician, 65(2):121-134

Casiwan, C.B., Janaiah, A., Francisco, S.R., Hossain, M., Narciso, J., Cabrera, E. and Hidalgo, F.C., 2003. Hybrid rice cultivation in the Philippines: early farm-level experiences. Economic and Political Weekly, 38 (25): 2502-2508.

Desamero, N.V. and Manigbas, N.L., 2017. Hybrid Rice Program-Rice R\&D Highlights 2017. Philippine Rice Research Institute. Science City of Muñoz, Nueva Ecija, Philippines, pp. 1-27. Retrieved from: http://www.philrice.gov.ph/wpcontent/uploads/2018/10/HRP.pdf

FAO (Food and Agriculture Organization), 2009. How to feed the world in 2050. High-Level Experts Forum.12-13 October 2009, FAO Headquarters in Rome, Italy. Retrieved from: http://www.fao.org/fileadmin/templates/wsfs/docs/expert_pap er/How_to_Feed_the_World_in_2050.pdf

Gaspar, M.G, Roque, A.S. and Gonzales, D.B., 2007. The pains of success: in hybrid rice commercialization in the Philippines. Maligaya Nueva Ecija: Philippine Rice Research Institute. $251 \mathrm{p}$.

Hasan, M.J., Kulsum, M.U., Rahman, M.H., Ali, M.H. and Mahmud, M.H., 2015. Genetic variability, correlation and path analysis for yield related traits in hybrid rice. Bangladesh Journal of Agriculture, 40: 91-96.
IRRI (International Rice Research Institute), 2013. Standard evaluation system for rice $\left(5^{\text {th }}\right.$ edition). International Rice Research Institute, P.O. Box 933, 1099 Manila, Philippines. 65 p.

Kolmogoroff, A., 1941. Confidence limits for an unknown distribution function. The Annals of Mathematical Statistics, 12: 461-463. https://doi.org/10.1214/aoms/1177731684

Lang, N.T., Pham, T.T.H., Pham, C.T., Tran, B.T., Buu, B.C. and Cho, Y.C., 2015. Breeding for heat tolerance rice based on markerassisted backcrossing in Vietnam. Plant Breeding and Biotechnology, 3(3): 274-281. https://doi.org/10.9787/PBB.2015.3.3.274

Manigbas, N. L. and Sebastian, L. S., 2007. Breeding for High Temperature Tolerance in the Philippines. Proceedings of the International Workshop on Cool Rice for a Warmer World, Huazhong Agricultural Univeristy, Wuhan, Hubei, China. March 26-30, 2007.

Mantel, N., 1967. A technique of disease clustering and a generalized regression approach. Cancer Research, 27: 209-220.

National Seed Industry Council (NSIC), 2019. Bureau of Plant Industry, Visayas Avenue, Diliman, Quezon City, Philippines 1104. Retrieved from: http://www.nseedcouncil.bpinsicpvpo. com.ph/counter.php?link=downloadables/nsic-rice.xlsx

Pearson, K., 1895. Notes on regression and inheritance in the case of two parents. Proceedings of the Royal Society of London, 58: 240-242. https://doi.org/10.1098/rspl.1895.0041

PhilRice (Philippine Rice Research Institute), 2007. PalayCheck system for irrigated lowland rice. Maligaya, Science City of Muñoz, 3119 Nueva Ecija. 90p.

PhilRice (Philippine Rice Research Institute), 2018. Maligaya, Science City of Muñoz, 3119 Nueva Ecija. Retrieved from: https://www.philrice.gov.ph/mestizo-1hybrid-good-yield-great-taste/

PhilRice (Philippine Rice Research Institute), 2019. Maligaya, Science City of Muñoz, 3119 Nueva Ecija. Retrieved from: https://www.pinoyrice.com/rice-varieties/

Philstar (Philstar Global Corporation), 2016. Unit 909 and 910, The Infinity Tower, 26th Street, Bonifacio Global City, Taguig City, Metro Manila, Philippines. Retrieved from: https://www.philstar.com/business/2016/06/24/1595961/dapushes-hybrid-rice-mindanao

Philstar Global Corporation (Philstar), 2002. Unit 909 and 910, The Infinity Tower, 26th Street, Bonifacio Global City, Taguig City, Metro Manila, Philippines. Internet link: https://www.philstar.com/business/agriculture/2002/06/09/16 3963/hybrid-rice-program-now-full-swing

Smirnov, N.V., 1939. On the estimation of the discrepancy and empirical curves of distribution for two independent samples. Bulletin of Moscow University, 2:3-16.

Sombilla, M.A. and Quilloy, K., 2014. Strengthening the Philippine rice seed system. ReSAKSS Policy Note 10. Washington, D.C.: International Food Policy Research Institute (IFPRI). Retrieved from: http://ebrary.ifpri.org/cdm/ref/collection/ p15738coll2/id/128875

STAR, version 2.0.1 2014. Biometrics and Breeding Informatics, PBGB Division, International Rice Research Institute, Los Baños, Laguna.

Taylor, R., 1990. Interpretation of the correlation coefficient: A basic review. Journal of Diagnostic Medical Sonography, 6: 35-39. https://doi.org/10.1177/875647939000600106

Tester, M. and Langridge, P., 2010. Breeding technologies to increase crop production in a changing world. Science, 327: 818-822. https://doi.org/10.1126/science. 1183700

Uddin, M.J., Abdullah, M.R. and Wazuddin, M., 2007. Correlation and path analysis of yield and yield contributing characters of hybrid rice. Journal of the Bangladesh Society for Agricultural Science and Technology, 4 (4\&3): 149-154.

Yuan, L.P., 1986. Hybrids rice in China. China Journal of Rice Science, 1:7-17. 